\title{
Development of Value Added Products from Mulberry Leaves
}

\author{
V. S. Ramya and S. Chandrashekar* \\ Department of Sericulture, College of Agriculture, University of Agricultural Sciences \\ (GKVK), Bengaluru - 560 065, Karnataka, India \\ *Corresponding author
}

\section{Keywords}

Mulberry leaves masala biscuit,

Organoleptic

evaluation, Macro

nutrient, micro

nutrient, anti-

nutrients and cost analysis.

\section{Article Info}

Accepted:

05 February 2020

Available Online:

10 March 2020
In the present fast growing rapidly changing global society, attaining good health has become a challenge for all age groups. Now a day's consumption of foods made from the leaves increased, but still, few are considered as wastes, but they are actually beneficial for health. The study was made to utilize mulberry leaves in different form in value-added product, thus reducing the wastage and providing inexpensive, healthy product. Mulberry leaves contain a good amount of high protein, vitamin $\mathrm{C}$, beta-carotene and calcium contents. It can be easily grown in different parts of India and hence can help to meet the recommended dietary allowance of various micronutrients and improve the health status of vulnerable groups. Four variations of mulberry leaves masala biscuit were developed using mulberry leaves in different proportions viz., $2.5,5,7.5,10$ per cent in preparation of masala biscuit with other commonly used ingredients. The acceptability of four variations of developed mulberry leaves masala biscuit were studied by evaluating different organoleptic characteristics by 21 semi trained panel member. Mulberry leaves masala biscuit proportion 7.5 per cent secured highest acceptability scores. Further proportion 3 was subjected for nutrient and cost analysis.

\section{Introduction}

Over the years, medicinal plants have been found useful in the treatment and management of various health problems. About $80 \%$ of the world population relies on the use of traditional medicine, which is predominantly based on plant material (WHO, 1993).

The genus Morus contains approximately 16 members of family Moraceae, occurring primarily in northern temperate regions with some extending into tropical areas of Africa and the South American Andes. There are 11 species distributed widely in China.

Genus Morus (Mulberry) is one of such example that consists of over 150 species, among these, $M$. alba L. is dominant (Srivastava et al., 2006). Generally, it is used as foliage to feed the silkworms (Bombyx mori L.) and ruminants (Arabshahi - Delouee and Urooj et al., 2007). 


\section{Plant description}

The plant is usually a monoecious shrub or a medium sized tree with a cylindrical stem and rough, brown, vertically fissured bark. Leaves are variable in size and shape, usually 5 to 7.5 $\mathrm{cm}$ long, often deeply lobed, margins serrate or crenate-serrate, apex acute or shortly acuminate, base cordate or truncate; 3 basal nerves, lateral nerves forked near the margins. Flowers are inconspicuous and greenish: male spikes (catkins) are broad, cylindrical or ovoid, female spikes are ovoid and stalked. Fruit (syncarp) consists of many drupes enclosed in a fleshy perianth, ovoid or subglobose, up to $5 \mathrm{~cm}$ long, white to pinkish white, purple or black when ripe (Anonymous, 2001).

\section{Reported phyto-constituents}

The leaves are a good source of ascorbic acid, with 2 to $3 \mathrm{mg} / \mathrm{g}$, of which over $90 \%$ is present in the reduced form. They contain carotene, vitamin B1, folic acid, folinic acid, and vitamin D. Volatile constituents identified in steam-distillates of the leaves are nbutanol, betagamma-hexenol, methyl-ethyl acetaldehyde, n-butyl aldehyde, isobutyl aldehyde, vale aldehyde, hex aldehyde, alphabeta-hexenal, methyl-ethyl ketone, methylhexyl ketone, butylamine, and acetic, propionic and isobutyric acids. The leaves also contain calcium malate, succinic, and tartaric acids, xanthophyll and isoquercitrin (quercetin 3-glucoside) and tannins (Anonymous, 2001).

New polyhydroxylated alkaloids, $(2 \mathrm{R}, 3 \mathrm{R}, 4 \mathrm{R})$ 2- hydroxymethyl-3,4-dihydroxy-pyrrolidine$\mathrm{N}$-propionamide from the root bark of $M$. AlbaL., and 4-O- $\alpha$-Dgalactopyranosylcalystegine B2 and $3 \beta$, 63- dihydroxynortropane from the fruits, were isolated by column chromatography using a variety of ion-exchange resins. Fifteen other polyhydroxylated alkaloids were also isolated (Asano et al., 2001). 1-deoxynojirimycin (DNJ), a polyhydroxylatedpiperidine alkaloid present in both leaves and bark, is known to be one of the most potent $\alpha$ - glycosidase inhibitors (Oku et al., 2006).

A newglycoprotein was purified from the aqueous methanolic extract of the root bark of $M$. alba which has been used as a component of antidiabetic remedy in Oriental medicine.

This new glycoprotein was named as Moran 20K (Kim et al., 1999). Mulberrofuran G and albanol B were isolated from the root bark of M. albaL. (Moraceae) (Chi et al., 2001). The purity of isolated compounds evaluated by reversed-phase high-performance liquid chromatography (HPLC) was above 95\% $(\mathrm{w} / \mathrm{w})$ and the structure of prenylated flavonoids used in the study was identified by spectral data analysis (Sohn et al., 2004).

\section{Methodology}

Four variations of mulberry leaves masala biscuit one control without mulberry leaf masala biscuit were developed by using mulberry leaves powder, refined wheat flour, green masala, sugar, baking powder,salt, butter. Developed variations of mulberry leaves masala biscuit were evaluated for organoleptic characteristics. Further highly accepted mulberry leaves masala biscuitwas analyzed for nutrient content and analysed for cost.

\section{Preparation of mulberry leaves powder}

The collected mulberry leaves were manually separated and the leaves were washed in tap water to remove extraneous matter. Fresh leaves were boiled for 5 minutes at $80^{\circ} \mathrm{C}$ where blanching is done to inhibit enzyme activity and then dried in tray drier at $60 \pm 5^{\circ} \mathrm{C}$ for 3 hours. 


\section{Development of mulberry leaves masala biscuit}

Four variations of mulberry leaves masala biscuit, prepared using dried mulberry leaves powder $(2.5,5,7.5$ and 5 per cent) and compared with control for sensory parameters.

\section{Results and Discussion}

\section{Nutrient analysis}

The nutrient content of highly accepted variation of mulberry leaves masala biscuit was analysed. Moisture free sample was used for analysis. The proximate composition (moisture, total protein, fat, fibre and total minerals) was carried out as per procedures prescribed by A.O.A.C. (1975). Carbohydrate content was calculated by difference method. Calcium was estimated by EDTA method. Trace elements (iron, copper, zinc and magnesium) were estimated by Atomic Absorption Spectrophotometer (Perkin R Elmer Model - 3110). The values for all nutrients were averages of triplicate value on dry weight basis.

The data of acceptability of four developed variations of mulberry leaves powder chutney were statistically analysed by one-way analysis of variance and ' $F$ ' values were calculated to find out the difference among the developed variations of herbal composite (Panse and Sukhatme, 1985)

\section{Cost calculation of the developed products}

Cost calculation was done for the best accepted products. This included cost of the ingredients and overhead charges at 30 per cent which include labour charge, electricity, machinery, packaging cost, etc. and then the total price was calculated for $100 \mathrm{~g}$ of the products.

\section{Observations and assessment}

The results obtained from the present investigation as well as relevant discussion have been summarized under following heads:

\section{Sensory evaluation of mulberry leaves masala biscuit (MLMB)}

Four variations of masala biscuit were prepared by incorporating dried mulberry leaves powder at 2.5, 5, 7.5 and10 per cent respectively and one control without dehydrated mulberry leaf powder. Sensory evaluation was carried out by using 9-point hedonic scale by 21 semi trained panellists.

All the variations of mulberry leaves masala biscuit varied significantly for appearance, texture, colour, flavour, taste and over all acceptability. The control had highest mean score for characteristics such as appearance (9.00), colour (8.50), taste (9.00), overall acceptability (8.75), texture (8.75) and flavour (9.00).

Among mulberry leaf masala biscuit variations, the one prepared by incorporating mulberry leaf powder at 7.5 per cent level was best accepted with scores for appearance (8.75), colour (8.50), texture (8.25), flavour (8.00), taste (8.50) and overall acceptability (8.50). Least mean scores were observed for appearance (7.00), colour (7.00), texture (8.50), flavour (8.50), taste (8.50) and overall acceptability (8.00) in MLMB at 2.5 per cent.

Drisya et al., (2013) conducted a Study to know the effect of dried $M$. koenigii leaves powder (DMKLP) on sensory attributes incorporated at different levels (5, 10 and 15 per cent) in cookies. Sensory evaluation showed that cookies with acceptable quality and typical curry leaf flavour could be obtained by incorporating DMKLP up to 10 
per cent. The colour of cookies changed from creamish white to greenish white. The surface cracking pattern was adversely affected at 15 per cent level. These results indicate that addition of DMKLP above 10 per cent adversely affected the quality characteristics of cookies.

Surabhi (2004) The products prepared by different varieties of amaranth viz., Pusabadichaulai (tricolour), Pusalalchaulai (red), and Pusachotichaulai (green) leaf powder incorporated at 5per cent and 10per cent and analysed for their organoleptic attributes. Biscuit prepared using Pusalalchaulai variety with 5per cent leaf powder had higher mean scores for all the sensory characteristics as compared to other two varieties. the biscuit prepared by Pusabadichaulai leaves powder at 5per cent incorporation were 'moderately desirable' in terms of appearance colour, flavour and overall acceptability.

Haneen (2015) investigated the dried Moringa oleifera leaves powder (DMLP) incorporation at different levels (5,10 and 15 per cent) in cookies and evaluated their sensory properties. Cookies prepared from blends containing 5 per cent level of dried Moringa flours did not differ significantly, results showed that cookies were acceptable in quality and typical Moringa leaf flavour could be obtained by incorporating DMLP up to 10 per cent $(\mathrm{P}<0: 05)$ from the control.

The study was made to utilize two types of leaves (drumstick leaf powder \& cauliflower leaf powder) in different proportions, thus reducing the wastage and providing inexpensive, healthy bakery product (cookies). The refined wheat flour was blended with DLP and CGLP in a different recipe in the ratios of 35,45 , and 55 per cent for the development of cookies. Moringa cookies and Brassica cookies were found to be highly acceptable at 35 per cent level of supplementation of drumstick leaves powder and cauliflower leaves powder with an overall acceptable score of 7.35 to 8.05 respectively (Shaik et al., 2018).

Among four variations, incorporation of mulberry leaf powder ranged from 2.5 per cent in chutney powder to 7.5 per cent in masala biscuit.

\section{Proximate composition of masala biscuit}

Mulberry leaves incorporated at 7.5 per cent in masala biscuit was best accepted among different levels of incorporation and evaluated for proximate composition.

Where control masala biscuit had moisture (2.6 per cent), protein (7.71 g), fat (21.6 g), fibre $(1.03 \mathrm{~g})$, ash $(2.6 \mathrm{~g})$, carbohydrate (64.4 g) and energy (482.6 Kcal) which is lower than Mulberry leaves masala biscuit at 7. 5per cent (MLMB) had moisture (3 per cent), protein $(8.9 \mathrm{~g})$, fat $(22.78 \mathrm{~g})$, fibre $(2.52 \mathrm{~g})$, ash (3 g), carbohydrate (59.8 g) and energy (483.82 Kcal). where moisture, fat, fibre, carbohydrate and energy are statistically significant and ash was statistically nonsignificant at 5 per cent. Nutrient composition of mulberry leaves masala biscuit at 7.5 per cent and control are presented in Table 3.

Hooda and Jood (2005) reported that biscuits supplemented with fenugreek leaves were analysed for nutrient composition, results revealed that biscuits contain moisture (3.19 per cent), fat (21.15 per cent), protein (10.1 per cent), fibre (2.37 per cent), ash (1.86 per cent) and carbohydrate (61.3 per cent).

Haneen (2015) prepared products using dried Moringa oleifera leaves powder (DMLP) and incorporated at different levels (5,10 and 15 per cent) in cookies and nutritional properties were evaluated. The results revealed that with 
incorporation of 5per cent of DMLP contains protein $(9.73 \mathrm{~g})$, dietary fibre $(2.63 \mathrm{~g})$, ash $(1.77 \mathrm{~g})$, fat $(22.69 \mathrm{~g})$, carbohydrate $(63.19 \mathrm{~g})$, energy (495.89 kcal) and minerals like $\mathrm{Zn}$ (3.90 mg), Fe (18.77 mg), Mn (1.37 mg), Ca (56.35 mg) in cookies were increased. The protein content increased from 8.91 to 9.73 , 10.38 and 9.77 per cent with addition of 5,10 and 15 per cent DMLP respectively and increase in the mineral contents with increase in drumstick leaves level.

Singh et al., (2009) developed biscuit with incorporation of amaranth leaf powder and conducted nutrient analysis of developed product, the results revealed that the biscuit had 1.87 per cent moisture, 17.29 per cent protein, 21.23 per cent fat, 2.45 per cent ash and 2.75 per cent fibre.

\section{Mineral composition of masala biscuit}

The difference in characteristics viz. zinc, iron, copper and manganese among the variations was found to be statistically significant at 5 per cent level for mulberry leaves masala biscuit.

Mulberry leaves masala biscuit (MLMB) at 7.5per cent which was best accepted among different levels of mulberry leaves were analysed for mineral contents and it contains zinc $(3.75 \mathrm{mg})$, iron (19.66 $\mathrm{mg}$ ), manganese (3.19 $\mathrm{mg})$, copper (5.68 $\mathrm{mg}$ ) and calcium (39.16 $\mathrm{mg})$.. where as in control zinc (2.34 $\mathrm{mg})$, iron (19.31 mg), manganese $(2.06 \mathrm{mg}$ ), copper (3.65 mg) and calcium (37.8 mg). Mineral composition of mulberry leaves masala biscuit isdepicted in Table 4. The results differ with Hooda and Jood (2005), Haneen (2015), Singh et al., (2009).

Hooda and Jood (2005) reported that biscuits supplemented with fenugreek leaf were analysed for nutrient composition, where biscuits prepared with fenugreek leaves contain contains minerals like calcium (57.4 per cent), iron (7.25 per cent) and zinc (3.89 per cent). Singh et al., (2009) developed biscuit with incorporation of amaranth leaf powder and conducted nutrient analysis of developed product, the results revealed that the biscuit contains calcium $(38.5 \mathrm{mg})$, iron $(6.71 \mathrm{mg})$ and zinc $(3.37 \mathrm{mg})$.

Haneen (2015), prepared products using dried Moringa oleifera leaves powder (DMLP) and incorporated at different levels (5,10 and 15 per cent) in cookies and nutritional properties were evaluated. The results revealed that with incorporation of 5per cent of DMLP contains minerals like zinc $(3.90 \mathrm{mg})$, Fe $(18.77 \mathrm{mg})$, Mn (1.37 mg), Ca (56.35 mg), Mg (98.87 mg) in cookies were increased.

\section{Anti-nutrient content of masala biscuit}

The difference in anti-nutrients like phytates and oxalates among the variations varied significantly. Masala biscuit was prepared using dehydrated mulberry leaves at different proportions and the best accepted masala biscuit at 7.5 per cent and analysed for antinutrient content. The masala biscuit without mulberry leaf contains phytic acid (110.25 $\mathrm{mg}$ ) and oxalate $(215.3 \mathrm{mg})$, tannin (0.606 $\mathrm{mg}$ ). Masala biscuit prepared using mulberry leaf contains phytic acid (109.52 mg) and oxalate $(213.542 \mathrm{mg})$, tannin $(0.595 \mathrm{mg})$ (Table 5). This study was similar with the study of Surabhi Singh (2004), studied the anti-nutrients contents of biscuits prepared by incorporating amaranth leaves. The oxalic content was $0.86 \mathrm{~g}$ and phytic acid $130.58 \mathrm{mg}$.

\section{Cost of production of best accepted mulberry leaves masala biscuit}

The production cost of the best accepted mulberry leaves masala biscuit ( 7.5 per cent) and control without mulberry leaves was calculated and depicted in the Table 25. The 
cost of raw material for control was 9.41and masala biscuit prepared with mulberry leaves was 9.32, production cost for control is 2.79 and for best accepted one is 2.796 and selling price for $100 \mathrm{gm}$ is masala biscuit for best accepted one was Rs.17.81 and for control was Rs.17.95. As per Shruthi (2018), the cost of preparation of masala biscuits with fenugreek leaves was calculated which includes overhead charges at 30 per cent of expenditure on manufacturing which includes labour cost, depreciation cost on machinery, equipment and building etc. was included where the cost of fenugreek masala biscuit was 21 rupees.

Table.1 Ingredients for masala biscuit preparation

\begin{tabular}{|c|c|c|c|c|c|c|}
\hline Sl. No. & Ingredients (g) & I & II & III & VI & Control \\
\hline $\mathbf{1}$ & Maida & 58.5 & 56 & 53.5 & 51 & 61 \\
\hline $\mathbf{2}$ & Green masala & 20 & 20 & 20 & 20 & 20 \\
\hline $\mathbf{3}$ & Sugar & 5 & 5 & 5 & 5 & 5 \\
\hline $\mathbf{4}$ & Baking powder & 1 & 1 & 1 & 1 & 1 \\
\hline $\mathbf{6}$ & Salt & 3 & 3 & 3 & 3 & 3 \\
\hline $\mathbf{7}$ & Butter & 10 & 10 & 10 & 10 & 10 \\
\hline $\mathbf{8}$ & Mulberry leaves & $\mathbf{2 . 5}$ & $\mathbf{5}$ & $\mathbf{7 . 5}$ & $\mathbf{1 0}$ & - \\
\hline
\end{tabular}

Table.2 Mean sensory score of mulberry leaves masala biscuit (MLMB)

\begin{tabular}{|c|c|c|c|c|c|c|}
\hline \multirow{2}{*}{ Product } & \multicolumn{5}{|c|}{ Sensory attributes } \\
\cline { 2 - 7 } & Appearance & Texture & Colour & Flavour & Taste & Overall acceptability \\
\hline MLMB (2.5 \%) & $7.00^{\mathrm{d}}$ & $8.50^{\mathrm{c}}$ & $7.00^{\mathrm{d}}$ & $8.50^{\mathrm{b}}$ & $8.50^{\mathrm{b}}$ & $8.00^{\mathrm{d}}$ \\
\hline MLMB (5 \%) & $7.00^{\mathrm{d}}$ & $9.00^{\mathrm{a}}$ & $7.00^{\mathrm{d}}$ & $8.50^{\mathrm{b}}$ & $9.00^{\mathrm{a}}$ & $8.00^{\mathrm{d}}$ \\
\hline MLMB (7.5 \%) & $8.75^{\mathrm{b}}$ & $8.50^{\mathrm{c}}$ & $8.25^{\mathrm{b}}$ & $8.00^{\mathrm{c}}$ & $8.50^{\mathrm{b}}$ & $8.50^{\mathrm{b}}$ \\
\hline MLMB (10 \%) & $7.50^{\mathrm{c}}$ & $8.25^{\mathrm{d}}$ & $7.50^{\mathrm{c}}$ & $7.75^{\mathrm{d}}$ & $8.25^{\mathrm{c}}$ & $8.25^{\mathrm{c}}$ \\
\hline Control & $9.00^{\mathrm{a}}$ & $8.75^{\mathrm{b}}$ & $8.50^{\mathrm{a}}$ & $9.00^{\mathrm{a}}$ & $9.00^{\mathrm{a}}$ & $8.75^{\mathrm{a}}$ \\
\hline F-test & $*$ & $*$ & $*$ & $*$ & $*$ & $*$ \\
\hline SEm士 & 0.025 & 0.02 & 0.024 & 0.025 & 0.028 & 0.022 \\
\hline CD @ 5 \% & 0.075 & 0.05 & 0.071 & 0.074 & 0.084 & 0.065 \\
\hline
\end{tabular}

*Significance, at 5per cent level, NS- Non significant, MLMB- Mulberry leaves masala biscuit (2.5 per cent), MLMB- Mulberry leaves masala biscuit (5 per cent), MLMB- Mulberry leaves masala biscuit ( 7.5 per cent), MLMB- Mulberry leaves masala biscuit (10 per cent).

Table.3 Proximate compositions of masala biscuit

\begin{tabular}{|c|c|c|c|}
\hline Proximate & Control & MLMB (7.5\%) & t value \\
\hline Moisture (\%) & 2.6 & 3 & $4.20^{*}$ \\
\hline Protein (g) & 7.71 & 8.9 & $48.40^{*}$ \\
\hline Fat (g) & 21.6 & 22.78 & $3.8^{*}$ \\
\hline Fibre (g) & 1.03 & 2.52 & $1.05^{*}$ \\
\hline Ash(g) & 2.66 & 3 & - \\
\hline CHO (g) & 64.4 & 59.8 & $27.115^{*}$ \\
\hline Energy (Kcal) & 482.6 & 483.82 & $5.24^{*}$ \\
\hline
\end{tabular}

T test -NS- non significant, * significant, MLMB- mulberry leaves masala biscuit 
Table.4 Mineral composition of masala biscuit

\begin{tabular}{|c|c|c|c|}
\hline Micro nutrients (mg) & Control & MLMB (7.5 \%) & t value \\
\hline Zinc & 2.34 & 3.75 & $39.09^{*}$ \\
\hline Iron & 19.31 & 19.66 & $7.4^{*}$ \\
\hline Manganese & 2.06 & 3.19 & $21.87^{*}$ \\
\hline Copper & 3.65 & 5.68 & $37.6^{*}$ \\
\hline Calcium & 37.8 & 39.16 & $70.4^{*}$ \\
\hline
\end{tabular}

T test- NS- non significant, * significant, MLMB- mulberry leaves masala biscuit

Table.5 Anti-nutrient contents of masala biscuit

\begin{tabular}{|c|c|c|c|}
\hline Anti-nutrients & Control & MLMB (7.5 \%) & t value \\
\hline Phytates (mg/100g) & 110.25 & 109.52 & $3.2^{*}$ \\
\hline Oxalates (mg/100g) & 215.3 & 213.542 & $7.95^{*}$ \\
\hline Tannin $\mathbf{~ m g / 1 0 0 g}$ & 0.606 & 0.593 & - \\
\hline
\end{tabular}

T-test, *Significance, NS- Non significant at 5per cent level, MLMB- Mulberry leaves masala biscuit (7.5 per cent), Control- with no mulberry leaf

Table.6 Production cost of mulberry leaves masala biscuit (per $100 \mathrm{~g}$ )

\begin{tabular}{|c|c|c|c|c|c|}
\hline \multirow[t]{2}{*}{ Ingredients } & \multirow{2}{*}{$\begin{array}{l}\text { Ingredients } \\
\text { cost } / \mathrm{kg}\end{array}$} & \multicolumn{2}{|c|}{ Control } & \multicolumn{2}{|c|}{7.5 per cent } \\
\hline & & $\begin{array}{l}\text { Ingredients } \\
\text { used (g) }\end{array}$ & $\begin{array}{c}\text { Price } \\
\text { Rs }\end{array}$ & $\begin{array}{l}\text { Ingredients } \\
\text { used (g) }\end{array}$ & $\begin{array}{c}\text { Price } \\
\text { Rs }\end{array}$ \\
\hline \multicolumn{6}{|c|}{ A. Raw material cost/kg (Total) } \\
\hline Mulberry leaves & 20 & - & - & 7.5 & 0.15 \\
\hline Maida & 35 & 61 & 2.13 & 53.5 & 1.87 \\
\hline Butter & 220 & 10 & 4.4 & 10 & 4.4 \\
\hline Green masala & 123 & 20 & 2.46 & 20 & 2.46 \\
\hline Baking powder & 160 & 1 & 0.16 & 1 & 0.16 \\
\hline Salt & 20 & 3 & 0.06 & 3 & 0.06 \\
\hline Sugar & 40 & 5 & 0.2 & 5 & 0.2 \\
\hline Yield (g) & & 100 & - & 100 & - \\
\hline \multicolumn{2}{|c|}{ Total cost Raw material } & - & 9.41 & - & 9.32 \\
\hline \multicolumn{2}{|c|}{$\begin{array}{c}\text { B. Production cost including machinery and } \\
\text { labour cost @ 30per cent of raw material } \\
\text { cost }\end{array}$} & & 2.79 & & 2.796 \\
\hline \multicolumn{2}{|c|}{ Sub total } & - & 12.2 & - & 12.11 \\
\hline \multicolumn{2}{|c|}{$\begin{array}{l}\text { C. Institutional charges @ } 10 \text { per cent } \\
(\mathrm{A}+\mathrm{B})\end{array}$} & & 2.16 & & 2.14 \\
\hline \multicolumn{2}{|c|}{ Sub total } & - & 14.36 & - & 14.25 \\
\hline \multicolumn{2}{|c|}{ D. Profit @ 10 per cent $(A+B+C)$} & & 3.59 & & 3.56 \\
\hline \multicolumn{2}{|c|}{ Cost per $100 \mathrm{~g}$} & - & 17.95 & - & 17.81 \\
\hline
\end{tabular}


Sieving refined flour and incorporation of mulberry leaves powder at different levels along with baking powder

Add curry leaves, chili, salt, butter

Kneading to soft dough

Spreading (uniform thickness)

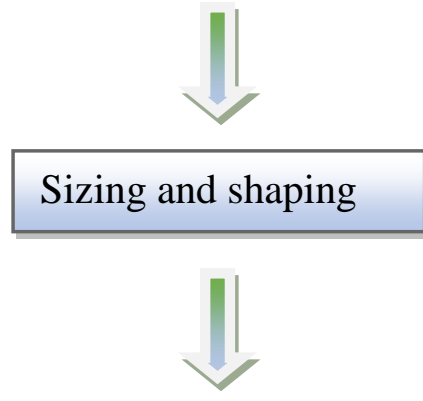

Baking at $160^{\circ} \mathrm{C}$ for

Cooling, packing and storing

Fig.1 Preparation of masala biscuit 


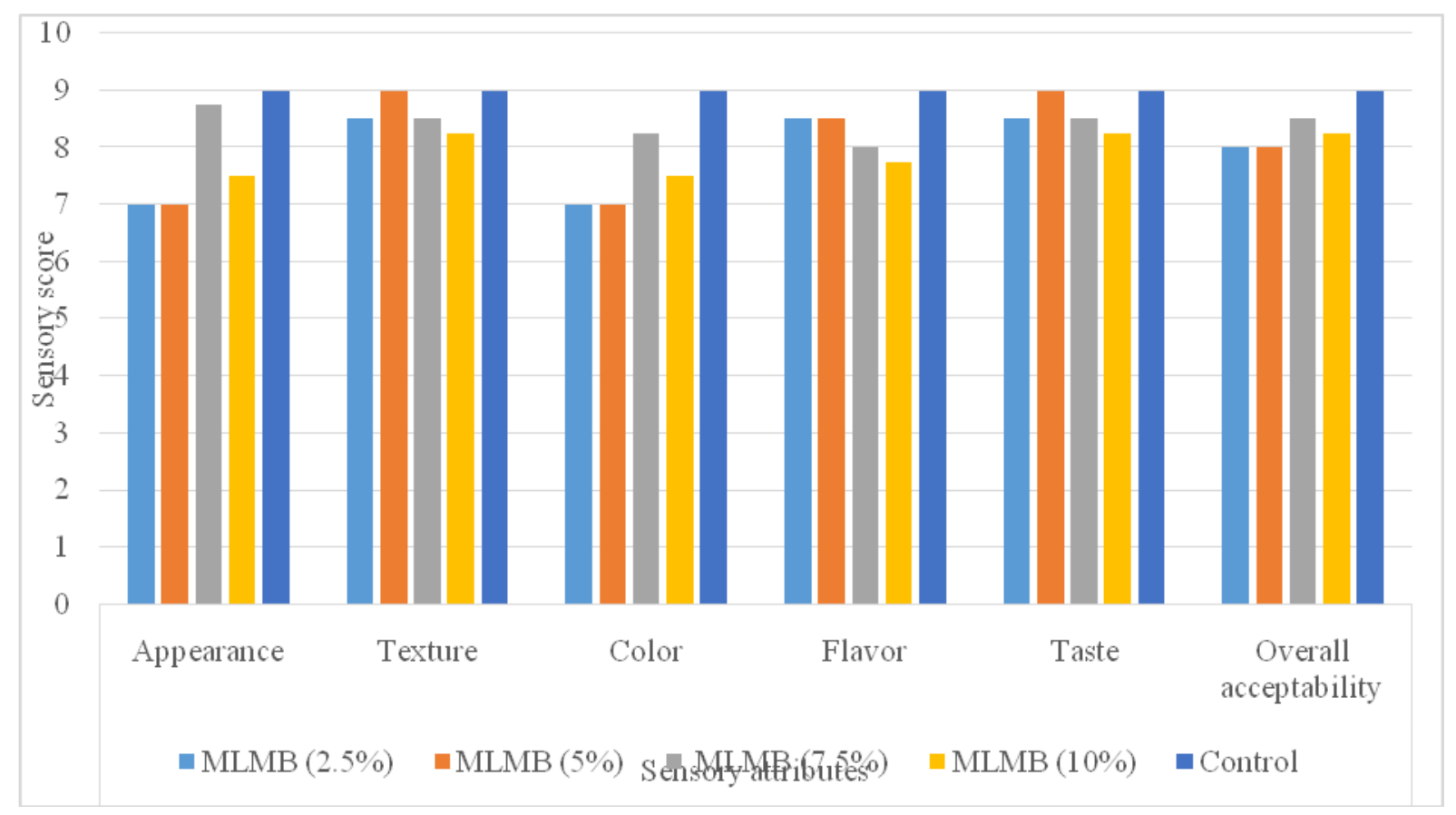

Fig.2 Mean sensory score of Mulberry leaves masala biscuit

Orally masala biscuit prepared using mulberry leaves at 7.5 per cent has been best accepted and it has highest proximate and mineral composition with less anti-nutrients compared to control hence it can be used in our daily diet as a nutrient rich product. Addition of dehydrated mulberry leaves increased the nutrient density of masala biscuit.

A remarkable increase in micronutrient content was observed. The nutrient density increased progressively with addition of mulberry leaves compared to control. Hence, value addition of traditional products with dehydrated mulberry leaves can be advocated as a feasible food based approach to combat micronutrient malnutrition.

\section{References}

A.O.A.C., 1980, Official methods of analysis, 13th edition. Association of official agricultural chemists, Washington, D. C. 2004.
Anonymous,2001, The Wealth of India, A Dictionary of Raw Materials and Industrial Products, Raw Materials, CSIR, PID, New Delhi. 6(LM): 429437.

Arabshahi, D, S. and Urooj, A.,2007, Antioxidant properties of various solvent extracts of mulberry (Morus indica L.) leaves. Food Chem. 102:1233-1240.

Asano, N., Yamashita, T., Yasuda, K., Ikeda, K., Kizu, H. and Kameda, Y., 2001, Polyhydroxylated alkaloids isolated from mulberry trees (Morus albaL.) and silkworms (Bombyx mori L.). J. Agric. Food Chem. 49:4208- 4213.

Hooda, S. and Jood, S., 2005, Organoleptic and nutritional evaluation of wheat biscuits supplemented with untreated and treated fenugreek flour. Food Chemistry. 90 (3): 427-435.

Shruthi, K. J. 2018, Development of therapeutic products from fenugreek seeds and leaves. Thesis (Unpublished), University of Agricultural Sciences, 
GKVK, Bangalore, 70.

singh, S., Punia, D. and Khetarpaul, N., 2009, Nutrient composition of products prepared by incorporating amaranth (Amaranthus tricolour) leaf powder. Nutr.Food Sci., 39 (3): 218- 226.
Singh,S., 2004, Formulation of calcium rich products incorporating amaranth leaves and their nutritional evaluation. Thesis M. Sc (unpublished), ccs Haryana Agricultural University Hisar - 125004.

\section{How to cite this article:}

Ramya. V. S. and Chandrashekar. S. 2020. Development of Value Added Products from Mulberry Leaves. Int.J.Curr.Microbiol.App.Sci. 9(03): 1321-1330.

doi: https://doi.org/10.20546/ijcmas.2020.903.154 